\title{
Comparison Between Physico-Chemical Properties of the Technical Cashew Nut Shell Liquid (CNSL) and those Natural Extracted from Solvent and Pressing
}

\author{
Francisco H. A. Rodrigues \\ Coordenação de Química, UVA
}

\author{
Francisco C. F. França \\ Faculdade de Educação, Ciências e Letras do Sertão Central, UECE
}

\author{
José R. R. Souza, Nágila M. P. S. Ricardo, Judith P. A. Feitosa \\ Departamento de Química Orgânica e Inorgânica, UFC
}

\begin{abstract}
Cashew nut shell liquid (CNSL) is a by-product of the cashew kernel industry, applied mainly to produce polymeric derivatives. The technical CNSL (CNSLT) was obtained industrially, extracted by roasting the cashew nut shells at temperatures between 180 and $200{ }^{\circ} \mathrm{C}$. Two methods were used to produce natural CNSL. For the extraction of CNSLNP, the cashew nut shells were pressed at room temperature. CNSLNS was extracted in hexane at room temperature and recovered at $50{ }^{\circ} \mathrm{C}$. A comparison was made of the composition determined by HPLC and properties generated by viscosity measurements and also by TG, DSC and IPDT (integral procedural decomposition temperature). Natural CNSLs displayed higher content of cardol and anacardic acid and lower percentage of cardanol than CNSLT. The higher content of cardanol in CNSLNS was the major difference between natural CNSLs. CNSLNP had higher levels of impurity, higher viscosity, lower thermoxidative stabilities and lower ebullition temperature. The CNSL obtained by cold solvent extraction and recovery at $50{ }^{\circ} \mathrm{C}$ better preserves the original properties of the liquid.
\end{abstract}

Keywords: Chemical composition, CNSL, DSC, extraction, LCC, thermogravimetry, viscosity.

\section{Introduction}

Cashew nut shell liquid (CNSL) is a by-product of the cashew industry. It is a cheap and renewable material and replaces phenols with some advantages ${ }^{[1]}$. This liquid has many biological and industrial applications due to the fact that it can easily react forming various derivatives, including polymers and resins ${ }^{[2-4]}$. The biological activities of CNSL components such as antitumor ${ }^{[5]}$, antioxidant ${ }^{[6]}$, gastroprotective ${ }^{[7]}$ and antibiotic ${ }^{[8]}$ have been reported. In industry, CNSL polymers and resins are widely employed as friction materials, surface coating, adhesives, laminates, rubber compounding, flame retardants, and anticorrosive paints ${ }^{[1]}$. They are also recently studied as rubber plasticizers ${ }^{[9]}$ and antioxidant ${ }^{[10]}$, in polyurethanes synthesis ${ }^{[11]}$, in the cure of epoxy resin ${ }^{[12]}$, and in well known phenol formaldehyde resin ${ }^{[13]}$.

The cashew nut liquid is extracted from the cashew nut's shell and represents approximately $25 \%$ of the cashews weight ${ }^{[4]}$, and $30-35 \%$ of the nut shells weight ${ }^{[14]}$. Many processes are used to extract the CNSL. They can be divided into two basic types: those that involve heating and those that are done in cold or room temperature. The heating process (roasting) can be achieved by open recipients or drums ${ }^{[2]}$. The cashews can also be heated by the actual CNSL in a process denominated as thermo - mechanic (hot oil process $)^{[4]}$. In the cold, the CNSL can be obtained by extrusion, in solvents or by pressing. The cashew's liquid obtained by the cold is denominated as natural CNSL and when extracted in hot is denominated technical CNSL.

The components of the CNSL vary a lot with the extraction process. In the natural CNSL they are: anacardic acid (46-65\%); cardol (15-31\%); cardanol (10-22\%) and traces of methyl-cardol (Figure 1$)^{[15,16]}$. The anacardic acids are thermically unstable and are easily decarboxylated during the hot extraction process. However, the technical CNSL should have a smaller or no percentage of anacardic acids. Therefore, its composition varies as it depends on the time and temperature to which the cashew was submitted. Normally the composition of the technical CNSL is: 60 to $95 \%$ cardanol, 4 to $19 \%$ cardol, 1 to $2 \%$ of anacardic acid, 0.3 to $10 \%$ of polymeric material and 1.2 to $4.1 \%$ of 2 -methylcardol ${ }^{[4,16,17]}$. The CNSL obtained with super critical $\mathrm{CO}_{2}$ presented cardanol as its main component ( 75 to $88 \%$ ), with its concentration depending on the operational parameters.

The application of CNSL depends on its composition. Much of the biological activities are associated with the anacardic acid, the main component of natural cashew liquid ${ }^{[18]}$. Cardol has been associated with several clinical pictures, such as contact dermatitis ${ }^{[19]}$. Antioxidant activity of CNSL on the thermal oxidation of cis-1,4-polyisoprene was greater than cardanol ${ }^{[10]}$. With its polymerizable side chain and phenolic group, cardanol is the most applied for polymer synthesis ${ }^{[16]}$.

In this study the physico-chemical properties of CNSLs obtained industrially (CNSLT) will be compared with the natural CNSL obtained via pressing at room temperature (CNSLNP) and with that CNSL extracted in solvent at room temperature but recuperated by heating at $50{ }^{\circ} \mathrm{C}$ (CNSLNS).

\section{Experimental}

\section{Materials}

The technical CNSL (CNSLT) and the CNSL natural pressing (CNSLNP) were provided by CIONE (Companhia Industrial de

Autor para correspondência: Judith P. A. Feitosa, Departamento de Química Orgânica e Inorgânica, Campus do Pici, Universidade Federal do Ceará, Caixa Postal 6021, CEP: 60455-760, Fortaleza, CE, Brasil. E-mail: judith@dqoi.ufc.br 
<smiles>[R]c1cccc(O)c1C(=O)O</smiles>

Anacardic acid<smiles>[R]c1cccc(O)c1</smiles>

Cardanol<smiles>[R]c1cc(O)cc(O)c1</smiles>

Cardol<smiles>[R]c1cc(O)c(C=C)c(O)c1</smiles>

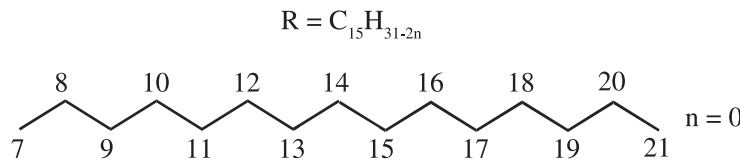

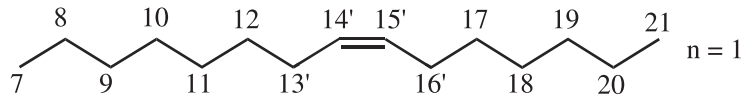<smiles>CCCC=CC#CCC=CCCCC</smiles><smiles>C=CCC=CCC#CCCC=CCCC</smiles>

Figure 1. Structure of main components of $\mathrm{CNSL}^{[16]}$.

Óleos do Nordeste) and the CNSL natural solvent (CNSLNS) was obtained from the nut shells from EMBRAPA (Empresa Brasileira de Pesquisa Agropecuária), Clones CCP09.

\section{Extraction from Cashew Nut Shell Liquid (CNSL)}

The CNSLT was obtained industrially, extracted by the roasting of the cashew nut's shell in temperatures of $180-200{ }^{\circ} \mathrm{C}$. For the extraction of the CNSLNP, the cashew nut's shell were cut in pieces to maximize its attainment through a manual pressing at room temperature, followed by filtration.

For the extraction of the CNSLNS, the cashew nut's shell were stocked overnight in a freezer to make the shells brittle. Subsequently, they were bi-sectioned by gentle hits along the axis which joins the two halves of the shells and submerged in hexane at room temperature. After this period of extraction (14 days) the hexane solution was roto-evaporated until a constant weight in temperature of $50{ }^{\circ} \mathrm{C}$.

\section{High Performance Liquid Chromatography (HPLC)}

The chromatograms were obtained in HPLC by the Shimadzu (LC-10AD), equipped with a photodiode network detector (SPD-M10A) in $280 \mathrm{~nm}$. For the separation, a C-18 reverse phase column was employed (Shimpack CLC-ODS (M) $4.6 \mathrm{~mm} \times 15 \mathrm{~cm}-5 \mu \mathrm{m}$ granulation) in a ratio of elution of $1.8 \mathrm{~mL} / \mathrm{min}$ in acetonitrile/water/acetic acid $(60: 20: 1)^{[16]}$.All the samples ( $25 \mathrm{mg}$ in $5 \mathrm{~mL}$ of acetonitrile) were injected with aliquots of $20 \mu \mathrm{L}$.

\section{Rheological properties}

The rheological measurements were performed in a Rheometric Brookfield model DV-III with CP-52 spindle. The viscosity curves $v s$. the shear rate were obtained at constant temperatures of $25 \pm 0.1{ }^{\circ} \mathrm{C}$ with water circulation of the thermostatic bath. The system was maintained for 10 minutes to reach the equilibrium, before the measurements were taken. The effect of the temperature on viscosity were verified in the bands of 5 and $54{ }^{\circ} \mathrm{C}$, with heating intervals between 2 to $3{ }^{\circ} \mathrm{C}$.

\section{Thermogravimetric analysis (TG)}

The thermogravimetric curves of the samples were obtained by the Shimadzu TGA-50 equipment, using a platinum crucible, atmosphere of synthetic air with a $50 \mathrm{~mL} / \mathrm{min}$ between temperature bands of 25 to $900{ }^{\circ} \mathrm{C}$, with heating rates of $10{ }^{\circ} \mathrm{C} / \mathrm{min}$. The mass of the CNSL samples analyzed was $10 \mathrm{mg}$. The parameters studied were: temperature in the beginning of decomposition $\left(\mathrm{T}_{\mathrm{i}}\right)$, peak temperature $\left(\mathrm{T}_{\text {max }}\right)$, residual mass at $700{ }^{\circ} \mathrm{C}$ and IPDT. The IPDT is a parameter defined by Doyle as "integral procedural decomposition temperature". It is a decomposition temperature, near the temperature of $50 \%$ of the total mass loss up to $900{ }^{\circ} \mathrm{C}^{[20]}$. It is a table of cumulative data which takes into account the full profile of the normalized curve. Although it was proposed in 1961, it continues to be used as one of the criteria for determining the stability of the materials ${ }^{[21,22]}$.

\section{Differential Scanning Calorimetry (DSC)}

The DSC curves were achieved by the Shimadzu DSC-50 equipment using platinum crucible and nitrogen atmosphere, with a flow of $50 \mathrm{~mL} / \mathrm{min}$ in the temperature range $25-500{ }^{\circ} \mathrm{C}$ at a heating rate of $10^{\circ} \mathrm{C} / \mathrm{min}$. The mass of the samples was $5 \mathrm{mg}$.

\section{Results and Discussion}

\section{CNSL composition}

Figure 2 demonstrates the HPLC chromatograms obtained for the CNSLT and the two CNSLNs. The samples presented distinct behaviors, even the two natural CNSLs. The identification of the peaks was based on the work by Setianto et al. ${ }^{[15]}$, Kumar et al. ${ }^{[16]}$, and Philip et al. ${ }^{[18]}$. The various peaks refer to the respective trienes, dienes and monoenes, whose retention time increased in the mentioned order. One approximate composition was determined by each area's peak (Table 1). Observe that the composition of the CNSLN obtained by solvent extraction is inside the band cited in the literature. On the other hand, the one obtained by pressing has an excessive content of cardol and a low level of the cardanol, as well as elevated levels of other materials or impurities. The CNSLT also presents an elevated level of cardol, which can be attributed to the fact the proper CNSLN already contains an elevated percentage of cardol. When comparing the CNSLN with the CNSLT, a decrease of the level of cardol, an increase in the level of cardanol and a drastic reduction of the anacardic acid percentage can be noticed due to its decarboxylation. An elevation of other components and impurities also occurs, which cannot be attributed to the polymeric material coming from the heating because, through the HPLC, only components of low molar mass are analyzed.

\section{Rheological studies}

Figure 3 shows the effect of shear rate on viscosity for the different CNSL samples. For all the samples, a near like Newtonian 
Table 1. Approximated compositions of the CNSL samples and comparisons with the literature data.

\begin{tabular}{cccccc}
\hline Constituent & \multicolumn{5}{c}{ Content (\%) } \\
\cline { 2 - 6 } & CNSLNS & CNSLNP & CNSLN $^{[15,16]}$ & CNSLT & CNSLT $^{[4,16,17]}$ \\
\hline Cardol & 34 & 42 & $15-31$ & 25 & $4-19$ \\
Anacardic acid & 45 & 47 & $46-65$ & 1 & $1-2$ \\
Cardanol & 17 & 3 & $10-22$ & 58 & $60-95$ \\
Other & 4 & 8 & $4-6$ & 16 & $5-8$ \\
\hline
\end{tabular}
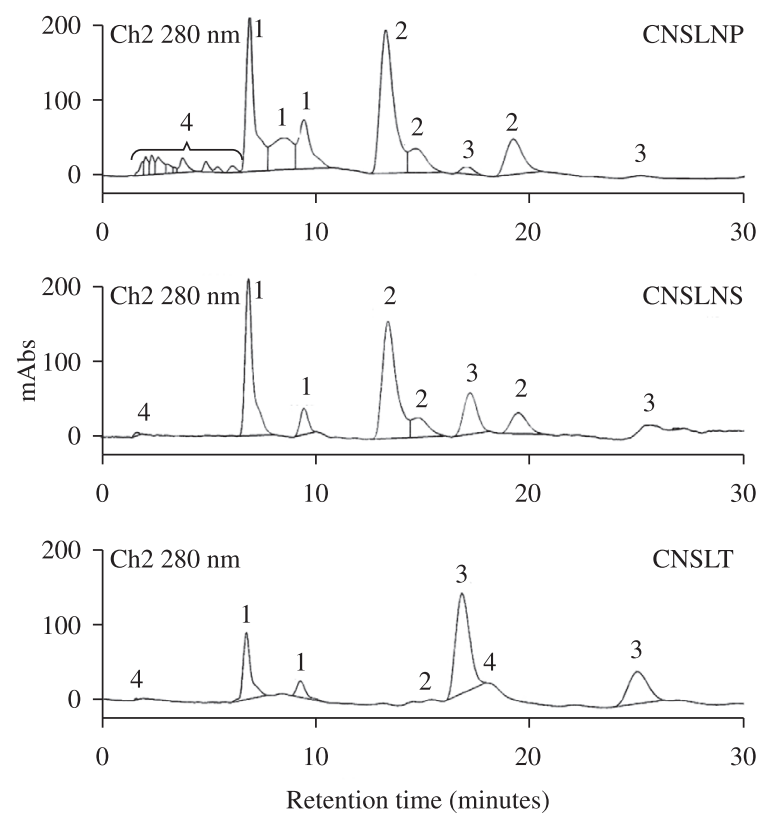

Figure 2. HPLC chromatograms obtained for CNLS. 1 (cardol), 2 (anacardic acid); 3 (cardanol) and 4 (other components).

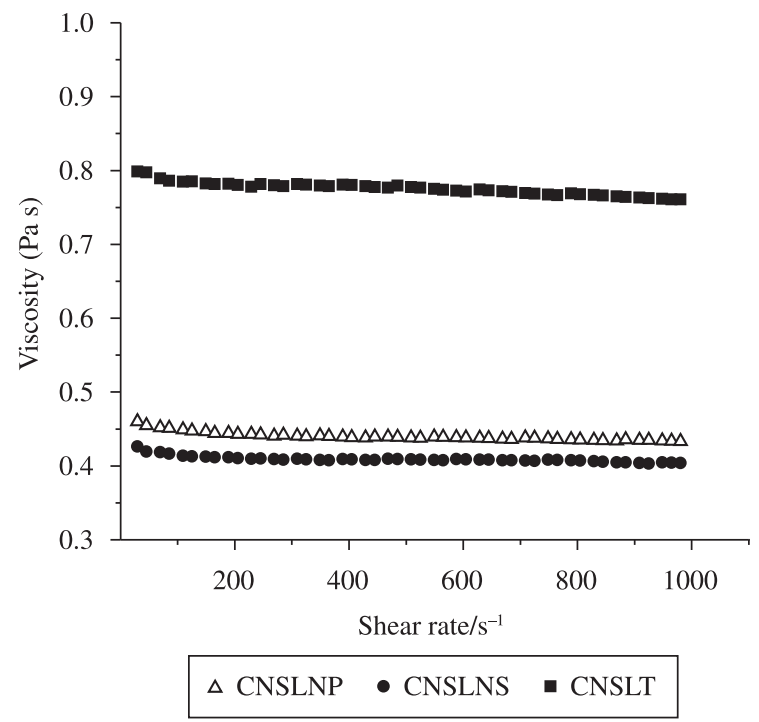

Figure 3. Viscosity in function of shear rate for the different CNSL samples.

behavior was observed in the range of shear measurements. This behavior was proved by the index value in the law of power, $n$, $\left(\eta=K \gamma^{(n-1)}\right.$, where $\eta$ is the viscosity, $\gamma$ is the shear rate and $K$ is a constant denominated consistency ${ }^{[23]}$. It was determined by the $\log \eta$ curves $v s . \log \gamma$ (not shown). The values of $n$ were $0.987,0.985$ and 0.990, respectively, for the CNSLNS, CNSLNP and CNSLT. Newtonian fluids present an $n$ value equal to 1.00. Consequently,

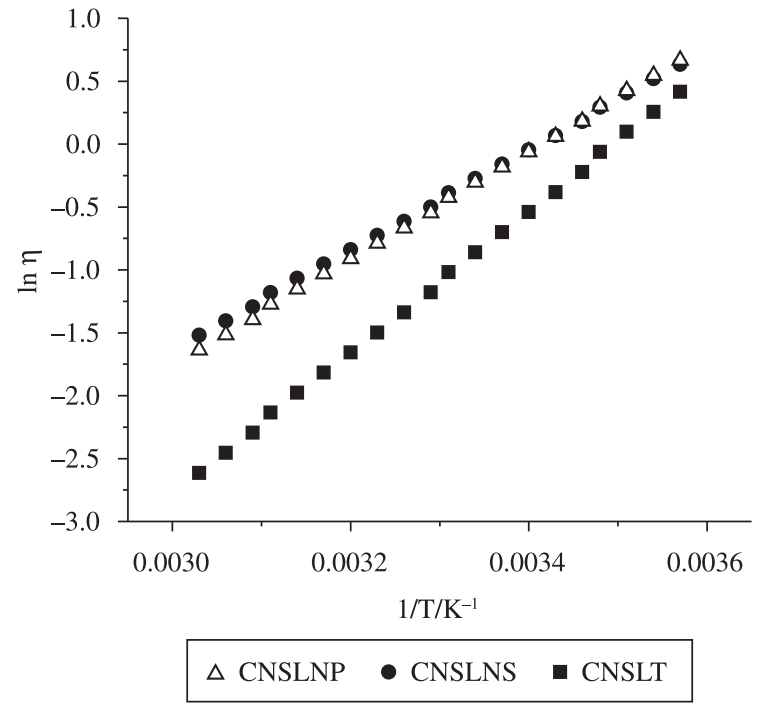

Figure 4. Activation energy of flow for the different CNSL samples.

the liquids of the cashew nut analyzed behaved essentially as Newtonian, but with a small degree of pseudoplasticity.

Large differences between the viscosity values, especially between the natural CNSLs (around $400 \mathrm{mPa} . \mathrm{s}$ ) and the CNSLT (780 mPa.s) can be viewed in Figure 3. Polymerized material presents much superior viscosity than materials of lower molar mass, which explains the difference observed. The standard viscosity at $25{ }^{\circ} \mathrm{C}$ for the CNSL is $150-600 \mathrm{mPa} . \mathrm{s}^{[24]}$. This indicates that the CNSLT provided by CIONE is not in the standard value, and that the roasting process used caused a degradation of the material and the production of even more polymeric material than foreseen, thus affecting its acceptance by the companies that acquire the product.

The two CNSLN samples demonstrate viscosity approximate to $400 \mathrm{mPa}$.s, even though the CNSLN extracted by pressing is more viscous ( $\eta=440 \mathrm{mPa} . \mathrm{s})$ than those extracted by solvent $(\eta=410 \mathrm{mPa} . \mathrm{s})$. Values of $\eta$ between 521 and $575 \mathrm{mPa} . \mathrm{s}$ were observed for CNSL extracted in $50{ }^{\circ} \mathrm{C}$ with various solvents, including hexane ${ }^{[14]}$. The level of polymerized material and therefore the degradation of the CNSLNS is inferior to those relative to the CNSL studied by Kumar et al. ${ }^{[14]}$.

The viscosity of organic substances of low molar mass in a constant temperature is dependent of two parameters: molar mass and the sum of the interactions of its constituent groups, which reflect in the intermolecular interactions ${ }^{[25]}$. The greater the molar mass and the interactions between groups, the greater the viscosity will be. Of the 30 most common groups of the organic compounds, the main contributions are those that involve $\mathrm{OH}, \mathrm{NH}$ and $\mathrm{COOH}$, being that the contribution of the $\mathrm{COOH}$ greater than that of $\mathrm{OH}$.

Considering that the lateral chain be similar to the main components of the CNSL, it is estimated that the order of the viscosity is cardanol $<$ cardol $<$ anacardic acid. The fact that the cardanol has a lower viscosity at $25{ }^{\circ} \mathrm{C}, 95 \mathrm{mPa} . \mathrm{s}^{[26]}$, much lower 
than the CNSLN's viscosity, supports the proposed order of viscosity.

The content of anacardic acid of natural CNSLs is very similar. However, the CNSLNS presents lower levels of cardanol and cardol than the CNSLNP. Since the cardol has a greater viscosity than the cardanol, the CNSLNS should have a lower viscosity, which was actually observed.

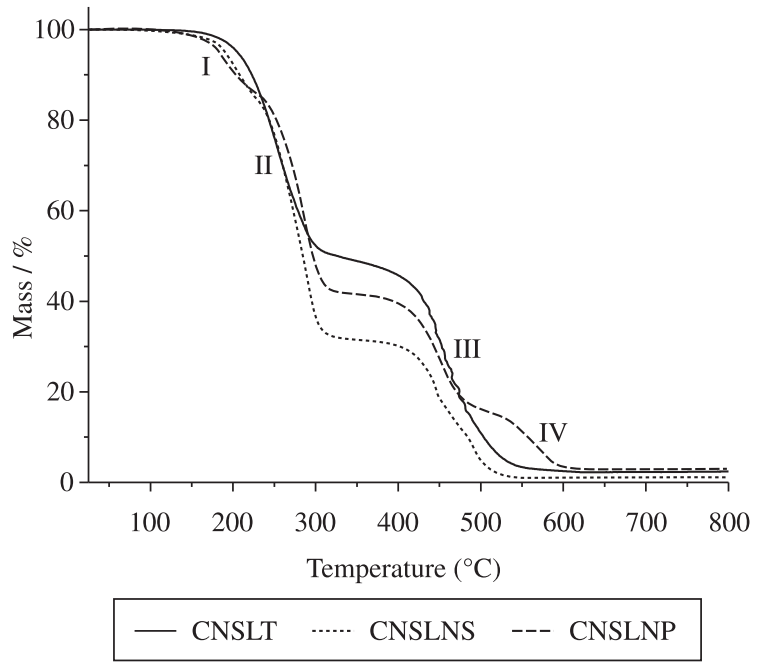

Figure 5. TG curves at a rate of $10{ }^{\circ} \mathrm{C} / \mathrm{min}$ and a flow rate of synthetic air for the different CNSL samples.

Table 2. Variables of the thermal degradation process of the CNSL samples, in synthetic atmosphere air with a flux of $10^{\circ} \mathrm{C} / \mathrm{min}$.

\begin{tabular}{|c|c|c|c|c|}
\hline \multicolumn{2}{|c|}{ Parameter } & CNSLNS & CNSLNP & CNSLT \\
\hline \multicolumn{2}{|c|}{$\mathrm{T}_{\mathrm{i}}\left({ }^{\circ} \mathrm{C}\right)$} & 115 & 109 & 148 \\
\hline \multicolumn{2}{|c|}{$\mathrm{T}_{\mathrm{f}}\left({ }^{\circ} \mathrm{C}\right)$} & 542 & 607 & 580 \\
\hline \multirow{4}{*}{$\mathrm{T}_{\max }\left({ }^{\circ} \mathrm{C}\right)$} & I & 199 & 192 & - \\
\hline & II & 276 & 282 & 256 \\
\hline & III & 453 & 447 & 470 \\
\hline & IV & - & 562 & - \\
\hline \multicolumn{2}{|c|}{ IPDT $\left({ }^{\circ} \mathrm{C}\right)$} & 282 & 291 & 309 \\
\hline \multicolumn{2}{|c|}{ residue at $700{ }^{\circ} \mathrm{C}(\%)$} & 1.7 & 3.7 & 2.2 \\
\hline
\end{tabular}

$\mathrm{T}_{\mathrm{i}}=$ Temperature of initial decomposition, $\mathrm{T}_{\mathrm{f}}=$ Temperature of final decomposition, $\mathrm{T}_{\max }=$ Temperature of maximum decomposition, IPDT = Integral procedural decomposition temperature, close to $50 \%$ total mass loss up to $900^{\circ} \mathrm{C}$.
The variation of the viscosity with the temperature can provide an important rheological parameter, which is the activation energy of flow, described by the Arrhenius-Frenkel-Eyring equation ${ }^{[27]}$ :

$$
\eta=\operatorname{Bexp}(\mathrm{E} / \mathrm{RT})
$$

where $\eta$ is the viscosity, B is a constant, $\mathrm{E}$ is the activation energy of flow, $\mathrm{R}$ is a universal constant of gases and $\mathrm{T}$ is an absolute temperature in Kelvin. The inclination of the straight line of $\ln \eta v s$. $\mathrm{T}^{-1}$ provides an activation energy of flow.

The activation energy of flow is the energy required to exceed the potential energy barrier relative to the displacement of a particle from a position of equilibrium to another during shearing. The values of E calculated from Figure 4 were: 52.7 ; 46.5 and $48.1 \mathrm{~kJ}^{\mathrm{mol}}{ }^{-1}$, for CNSLT, CNSLNS and CNSLNP, respectively. The highest value of E presented by CNSLT is due to the presence of polymerized material. The lowest value registered by the CNSLNS should be related to the lowest medium molar mass since it contains more cardanol (MM medium 301.5 g. $\mathrm{mol}^{-1}$ ). Cardol and anacardic acid have a medium molar mass of 315.4 and 342.9 g.mol ${ }^{-1}{ }^{[15]}$. The cardanol presents $\mathrm{E}$ value of $45.4 \mathrm{~kJ} \cdot \mathrm{mol}^{-1}{ }^{[28]}$, in agreement with the proposed explanation.

\section{Thermogravimetric analysis (TG)}

The TG curves in the atmosphere of synthetic air for the three samples of CNSL presented different profiles and parameters (Figure 5, Table 2). The beginning of the degradative process occurred in temperatures $\left(\mathrm{T}_{\mathrm{i}}\right)$ close to $110{ }^{\circ} \mathrm{C}$ for the natural CNSLs and $148{ }^{\circ} \mathrm{C}$ for the technical CNSL (heated at $180-210{ }^{\circ} \mathrm{C}$ ). The highest values of the IPDT for the CNSLT also indicate higher thermoxidative stability in comparison to other natural CNSLs. In addition to the presence of the polymerized material, the lower anacardic acid percentage (1\%) (Table 1) - the least stable of the CNSL components, and a higher percentage of cardanol - the most stable of components, can provide an explanation for the difference in thermoxidative stability. Cardanol, for example, presents $T_{i}, T_{f}$ and IPDT of $165 ; 650$ and $293{ }^{\circ} \mathrm{C}^{[16]}$, indicating its greater stability among the major CNSL components.

The natural CNSL obtained by pressing presents one thermal event $\left(\mathrm{T}_{\max } 562{ }^{\circ} \mathrm{C}\right)$ more than the three events registered for the CNSLNS and a greater residue. This greater level in residue, and the levels of the other components obtained by HPLC (Table 1) indicate that the pressing of the shells produced a more impure CNSL.

\section{Diferencial Scanning Calorimetry (DSC)}

The DSC curves for the different CNSL samples (data not showed) indicate that the CNSLT boils at a significant greater

Table 3. Comparison among CNSL samples.

\begin{tabular}{|c|c|c|c|c|}
\hline \multicolumn{2}{|c|}{ Characteristics } & \multirow{2}{*}{$\begin{array}{c}\text { CNSLNS } \\
34\end{array}$} & \multirow{2}{*}{$\begin{array}{c}\text { CNSLNP } \\
42\end{array}$} & \multirow{2}{*}{$\frac{\text { CNSLT }}{25}$} \\
\hline \multirow{4}{*}{ Composition* (wt. (\%)) } & cardol & & & \\
\hline & anacardic acid & 45 & 47 & 1 \\
\hline & cardanol & 17 & 3 & 58 \\
\hline & other & 4 & 8 & 16 \\
\hline \multirow{2}{*}{ Flow } & Viscosity at $25^{\circ} \mathrm{C}$ (mPa.s) & 410 & 440 & 780 \\
\hline & Activation energy of flow $\left(\mathrm{kJ} \cdot \mathrm{mol}^{-1}\right)$ & 46.5 & 48.1 & 52.7 \\
\hline \multirow{3}{*}{ Thermal stability in air } & $\mathrm{T}_{\mathrm{i}}\left({ }^{\circ} \mathrm{C}\right)$ & 115 & 109 & 148 \\
\hline & $\operatorname{IPDT}\left({ }^{\circ} \mathrm{C}\right)$ & 282 & 291 & 309 \\
\hline & residue at $700{ }^{\circ} \mathrm{C}(\%)$ & 1.7 & 3.7 & 2.2 \\
\hline Volatility & boiling temperature $\left({ }^{\circ} \mathrm{C}\right)$ & 179 & 172 & 283 \\
\hline
\end{tabular}

*Without polymerized materials. 
temperature $\left(283{ }^{\circ} \mathrm{C}\right)$ than the natural $\mathrm{CNSL}$ (pressing at $172{ }^{\circ} \mathrm{C}$, solvent at $179{ }^{\circ} \mathrm{C}$ ). The boiling of the cardanol was registered at $285^{\circ} \mathrm{C}^{[28]}$, very close to the temperature registered for the CNSLT, which contains cardanol as its main constituent.

\section{Final comparison}

A final comparison among the two natural and the technical CNSL can be seen in Table 3. The CNSLT presents a higher viscosity and activation energy of flow, which must be associated with higher levels of polymerization. The thermoxidative stability can be compared through $\mathrm{T}_{\mathrm{i}}$ and IPDT. As the IPDT takes the whole mass loss process into consideration, including those that take place in very high temperatures, the most important parameter in this case is the temperature in which the loss of mass starts, taking place the degradation of the material, ie, the $\mathrm{T}_{\mathrm{i}}$. In thermoxidative stability terms, the order is as follows: CNSLT > CNSLNS > CNSLNP. The highest residue at $700{ }^{\circ} \mathrm{C}$ and highest content of the other components in the natural CNSL indicate higher contents of other components/impurities.

\section{Conclusions}

The natural and technical cashew nut liquids presented composition inside the respective bands, with the natural liquids showing a higher level of anacardic acid and cardanol than the technical. A small percentage of the anacardic acid is still present in the technical CNSL, which presents viscosity superior to the average limit. The attainment process by pressing produces a CNSL with higher levels of impurity, higher viscosity, lower thermoxidative stabilities and lower boiling temperature. The CNSL obtained by solvent extraction with cold and recovery at $50{ }^{\circ} \mathrm{C}$ preserves better the original properties of the liquid, meaning that it is considered the more adequate option if a mixture of cardol, cardanol and anacardic acid is desirable for a specific application.

\section{Acknowledgements}

The authors would like to thank Dr. Ícaro G. P. Vieira for HPLC, CAPES and CNPq by the scholarships provided, and INCTINOMAT by financial support. CIONE and EMBRAPA were also acknowledged by the technical CNSL donation and nut shell supply.

\section{References}

1. Lubi, M. C. \& Thachill, E. B. - Des. Monomers Polym., 3, p.123 (2000).

2. Patel, R. N.; Bandyopadhyay, S. \& Ganesh, A. - Bioresour. Technol., 97, p.847 (2006).

3. Branchhor \& Baid, R. - Plant Arch., 7, p.497 (2007).

4. Mazzetto, S. E.; Lemonaco, D. \& Mele, G. - Quim. Nova, 32, p.732 (2009).

5. Kubo, I.; Ochi, M.; Viera P. C. \& Komatsu, S. - J. Agric. Food Chem., 41, p.1012 (1993).
6. Trevisan, M. T. S.; Pfundstein, B.; Haubner, R.; Würtele, G.; Spiegelhalder, B.; Bartsch, H. \& Owen, R. W. - Food Chem. Toxicol., 44, p.188 (2006).

7. Morais, T. C.; Pinto, N. B.; Carvalho, K. M. M. B.; Rios, J. B.; Ricardo, N. M. P. S.; Trevisan, M. T. S.; Rao, V. S. \& Santos F. A. - Chem-Bio. Interact., 183, p.264 (2010).

8. Chelikani, R.; Kim, Y. H.; Yoon, D. Y. \& Kim, D. S. - Appl. Biochem. Biotechnol., 157, p.263 (2009).

9. Souza, F. G.; Soares, B. G.; Siddaramaiah, S.; Barra G. M. O. \& Hebst, M. H. - Polymer, 47, p.7548 (2006).

10. Rodrigues, F. H. A.; Feitosa, J. P. A.; Ricardo, N. M. P. S.; França, F. C. F. \& Carioca, J. O. B. - J. Braz. Chem. Soc., 17, p.265 (2006).

11. Athawale, V. \& Shetty, N. J. - J. Polym. Mater., 26, p.149 (2009).

12. Mattew, G.; Rhee, J. M.; Hwang, B. S. \& Nah, C. - J. Appl. Polym. Sci., 106, p. 178 (2007).

13. Parameswaran, P. S.; Abraham, B. T. \& Thachil, E. T. - Prog. Rubber Plast. Recycl. Technol., 26, p.31 (2010).

14. Kumar, P. S.; Kumar, N. A.; Sivakumar, R. \& Kaushik, C. - J. Mater. Sci., 44, p.5894 (2009).

15. Setianto, W. B.; Yoshikawa, S.; Smith Jr., R. L.; Inomata, H.; Florusse, L. J. \& Peters, C. J. - J. Supercrit. Fluids, 48, p.203 (2009).

16. Kumar, P. P.; Paramashivappa, R.; Vithayathil, P. J.; Rao, P. V. S. \& Rao, A. S. - J. Agric. Food Chem., 50, p.4705 (2002).

17. Ikeda, R.; Tanaka, H.; Uyama, H. \& Kobayashi, S. - Polymer, 43, p.3475 (2002).

18. Philip, J. Y. N.; Francisco, J. C.; Dey, E. S.; Buchweishaija, J.; Mkayula, L. L. \& Ye, L. - J. Agric. Food Chem., 56, p.9350 (2008).

19. Diogenes, M. J. N.; Vilar, M. D. O. L. L.; Diogenes, J. A. C. N.; de Morais, S. M.; Serrer, M. A. R.; de Andrade A. R. C.; Costa, E. B. \& Alchorne, A. O. A. - Contact Derm., 52, p.293 (2005).

20. Doyle, C. D. - Anal. Chem., 33, p.77 (1961).

21. Chiang, C. L. \& Hsu S. W. - Polym. Int., 59, p.119 (2010).

22. Cunha, P. L. R.; Maciel, J. S.; Sierakowski, M. R.; de Paula, R. C. M. \& Feitosa, J. P. A. - J. Braz. Chem. Soc., 18, p.85 (2007).

23. Cowie, J. M. G.; Arrighi, V. A. - "Polymers: chemistry and physics of modern materials", 3rd ed., CRC Press, Boca Raton (2008).

24. Silva, M. C. D.; Conceição, M. M.; Fernandes Jr, V. J.; Santos, I. M. G. \& Souza, A. G. - Congresso de Biodiesel (2006).

25. Marrero-Morejon, J. \& Pardillo-Fontdevila, E. - Chem. Eng. J., 79, p.69 (2000).

26. Rodrigues, F. H. A.; Souza, J. R. R.; França, F. C. F.; Ricardo, N. M. P. S. \& Feitosa, J. P. A. - e-Polymers, 081 (2006).

27. Vinogradov, G. V. \& Malkin, A. Ya. - "Rheology of polymers, viscoelasticity and flow of polymers", Moscow (1980).

28. Rios, M. A. S.; Nascimento, T. L.; Santiago, S. N. \& Mazzetto, S. E. Energy Fuels, 23, p.5432 (2009).

Enviado: $15 / 07 / 10$ Aceito: $10 / 10 / 10$

DOI: $10.1590 / \mathrm{S} 0104-14282011005000028$ 